DOCTRINA

\title{
Propiedad intelectual en Cuba: Una mirada crítica a su reconocimiento constitucional
}

\author{
Intellectual property in Cuba: A critical look at its constitutional recognition
}

\author{
Mabel Cándano Pérez \\ Universidad Autónoma, Chile \\ Marta Moreno Cruz \\ Universidad de La Habana, Cuba
}

\begin{abstract}
RESUMEN El objetivo del presente estudio es determinar la necesidad de refrendar constitucionalmente el reconocimiento y protección de los derechos intelectuales en Cuba, a partir de un análisis teórico y de derecho comparado del tema. La Constitución cubana de 1976 no reconoce expresamente a los derechos intelectuales, dada la polémica en torno a que estos derechos puedan constituir un freno para el acceso al conocimiento y la innovación. No obstante, en esta investigación proponemos que los derechos intelectuales sean consagrados como derechos constitucionales, lo cual constituye un estímulo para la creación y difusión de dicho conocimiento en los diversos campos del quehacer humano. La nueva constitución puesta en vigor en Cuba en este año 2019 ya reconoce expresamente este tipo de derechos.
\end{abstract}

PALABRAS CLAVE Propiedad intelectual, constitución, intelecto humano, derechos intelectuales.

ABSTRACT The objective of this study is to determine the need to constitutionally endorse the recognition and protection of intellectual rights in Cuba, based on a theoretical and comparative law analysis of the subject. The Cuban Constitution of 1976 does not expressly recognize intellectual rights, given the controversy that these rights may constitute a brake on access to knowledge and innovation. However, in this research we propose that intellectual rights be consecrated as constitutional rights, which constitutes a stimulus for the creation and dissemination of said knowledge in the various fields of human endeavor. The new constitution put into effect in Cuba in this year 2019, already expressly recognizes this type of rights. 
KEYWORDS Intellectual property, constitution, human intellect, intellectual rights.

\section{Introducción}

La fundamentación de la necesidad y justificación de los derechos intelectuales ha sido objeto de varias polémicas, a partir de las cuales se han esgrimido diversas teorías. Así, encontramos la teoría del derecho natural, la cual sostiene que todo hombre posee un derecho natural de propiedad sobre sus propias ideas, el cual debe ser reconocido y protegido. Otra corriente argumenta la necesaria compensación o premio a todo el que ha ofrecido un servicio a la sociedad. Una tercera doctrina destaca que los derechos intelectuales significan ineludiblemente una promoción o incentivo al progreso industrial, y muy vinculada a esta concepción, hay quienes fundamentan que el sistema de propiedad intelectual contribuye a la difusión tecnológica de las ideas, a lograr la publicidad de las mismas y que trasciendan al acervo público (Machlup y Penroese, 1950).

Por tanto, los derechos intelectuales, a partir de las fundamentaciones de las teorías anteriores, son los únicos monopolios legalmente reconocidos, toda vez que el titular de estos derechos, en el territorio que los tenga registrados y durante el plazo de vigencia, tiene la facultad legal de excluir a otros del derecho al uso, según los términos explicitados en las normas y con las limitaciones señaladas. Por ello, se plantea que constituyen posiciones monopólicas establecidas y reconocidas, pero su ejercicio abusivo puede afectar el funcionamiento del mercado y los intereses públicos, especialmente en sectores como la alimentación, la salud pública, la educación y la cultura.

En tanto, la doctrina está conteste en afirmar que la propiedad intelectual otorga a su titular un derecho exclusivo y excluyente sobre su objeto, lo cual viene determinado por la propia naturaleza de tales derechos. A la vez es un estímulo a la investigación y contribuye al desarrollo económico por la introducción de estos resultados en la sociedad, si dichos mecanismos se utilizan de forma acertada. Ello justifica la existencia de los derechos intelectuales, cuya teoría fundamental se basa en la necesidad de la humanidad de tener acceso a los frutos del conocimiento humano y de estimular a los creadores a desarrollar un trabajo que beneficie a todos en general. ${ }^{1}$

En ese sentido, la creación y la innovación son parte esencial de la vida en todas sus esferas y, así, para cualquier rama de la economía constituye un componente básico. Por un lado, se afecta a los titulares de los derechos de propiedad intelectual de manera positiva, por ser la remuneración de la actividad creadora un incentivo para éstos e impedir que la competencia los utilicen. Mientras, por otro, desde una visión

1. Consúltese en la doctrina: Hernández Rodríguez (2011: 107-112); Fernández-Nóvoa, Otero Lastres y Botana Agra (2013: 485-487) y Mitelman (2015: 358). 
negativa, todos los competidores pueden ver cerrado el mercado total o parcialmente en función de sus prestaciones, por tanto el acceso al mismo supone infringir los derechos de propiedad intelectual de otro competidor.

En virtud de lo anterior, fundamentar las bases o principios básicos de los derechos intelectuales para lograr la protección constitucional de estos en la Carta Magna es una necesidad en el mundo actual.

Así, constituye una gran oportunidad para las personas naturales y organizaciones económicas, el hecho de que exista voluntad política para que el impacto de los avances científicos y tecnológicos se revierta en beneficio de la sociedad. Sin embargo, esta política debe ir acompañada de una estrategia de reconocimiento y protección de la creación, y que no solo se refleje en el conjunto de normas específicas dispuestas, sino que se demuestre con el debido reconocimiento constitucional.

Por consiguiente, el objetivo principal de este trabajo es demostrar que es viable el reconocimiento constitucional de los derechos intelectuales en Cuba, sobre la base de que el sistema cubano por esencia es protector de la voluntad popular contenida en el texto constitucional y de los derechos fundamentales reconocidos a las personas. Por tanto, la posibilidad de asumir el perfeccionamiento de los mecanismos jurídicos de protección de la propiedad intelectual e industrial puede lograrse en el marco político, jurídico y social que el sistema ha fijado.

Para desarrollar lo anterior, inicialmente analizaremos la importancia de la propiedad intelectual para el desarrollo económico, social y cultural, pues nos permitirá entender por qué estos derechos merecen una protección distinta; examinaremos el estado de la cuestión en el derecho comparado, haciendo especial énfasis en el derecho estadounidense, el derecho europeo y las constituciones de América Latina; a continuación, estudiaremos la Constitución Política de Cuba de 1976 y sus principales fundamentos; por último, a fin de argumentar la importancia de la protección, regulación y defensa constitucional de estos derechos en Cuba, haremos referencia a la vigente Constitución cubana de 2019 teniendo en cuenta el desarrollo económico, social y cultural actual de la isla en este campo.

\section{¿Por qué debe protegerse y promoverse la propiedad intelectual?}

La actividad de propiedad intelectual surge y ha evolucionado con dos objetivos fundamentales: primero, ofrecer un estatus a los derechos patrimoniales y morales del creador derivados de sus creaciones y a los derechos de la sociedad de acceder a las mismas; en segundo lugar, promover la creación, divulgación y aplicación de los resultados y así contribuir al desarrollo económico y social, personal y humano. ${ }^{2}$

2. «Understanding industrial property», Worlde Intellectual Property Organization, 2016, disponible en http://bit.ly/2x26ghD. 
En estas direcciones se ha desarrollado la actividad en cada país, lo cual ha cobrado gran transcendencia en la vida de las personas, por lo que tutelar estos derechos resulta sumamente necesario, tanto para los creadores como para la comunidad en general. Lo anterior viene dado porque tanto el progreso como el bienestar de la humanidad dependen de su capacidad de crear e inventar nuevas obras en las esferas de la tecnología y la cultura. Por tanto, la protección jurídica de las nuevas creaciones alienta a destinar recursos adicionales a la innovación y, de ahí, la promoción y la protección de la propiedad intelectual estimulan el crecimiento económico, generan nuevos empleos e industrias y enriquecen y mejoran la calidad de vida de la población en general.

Así, la propiedad intelectual es un campo sumamente amplio, y por naturaleza complicado, que en cualquiera de los niveles en que tenga lugar requiere de una estructura desde el punto de vista constitucional, administrativo, jurídico y económico que se encargue de dictar los términos y condiciones en que se efectuarán los registros, brindar servicios de información especializados, asesorar en todo el proceso a los creadores e innovadores y -muy importante-capacitar a las personas involucradas potencialmente en la actividad.

Es oportuno aclarar que los derechos de propiedad intelectual dentro de la sociedad se hallan en un constante espectro de actualización y dinámica en el mundo, más allá de las propias conceptualizaciones iniciales que hicieron posible su evolución, teniendo en cuenta la importancia que para el desarrollo económico, social, personal y humano poseen. La falta de cultura en esta materia y la indebida gestión de los activos intangibles como parte del patrimonio personal, o de las empresas, trae consigo que no se valoren, se protejan, se comercialicen ni se defiendan con acierto estos derechos (Banco Mundial, 1999: 18).

\section{La propiedad intelectual juega un importante papel en la economía}

Como hemos adelantado, la propiedad intelectual tiene significado y trascendencia multifacética y multidisciplinaria en el acontecer económico, ya que como activos inmateriales adquieren valor en el tráfico comercial. ${ }^{3}$ Por ende, está presente en las más diversas actividades, como investigación, desarrollo y tecnología; los servicios de información tecnológica, económica, legal, de promoción, publicidad, exposición, divulgación o cualquier forma de comunicación oral o escrita relativa a las creaciones intelectuales; en la formación académica pre y postgraduada; en el registro y autorización sanitaria y comercial de productos farmacéuticos, plaguicidas y variedades vegetales; la planificación económica y financiamiento estatal, institucional y empresarial; y actividades dirigidas al reconocimiento moral y material del esfuerzo creador.

3. Para ampliar sobre este tema puede verse Corberá Martínez (2017: 35-37). En cuanto a la teoría económica utilitaria, véase Hunter (2012: 16-17). 
En este contexto, y visto lo anterior, consideramos que el conocimiento se expresa a través de las personas, las instituciones y las nuevas tecnologías y adopta formas que desde hace mucho tiempo han sido consideradas un motor esencial del crecimiento económico (Banco Mundial, 1999: 18). ${ }^{4}$ Por ende, dentro del comercio internacional, uno de los sectores de crecimiento más rápido es el comercio de los bienes y servicios de alta tecnología, los cuales requieren un alto nivel de conocimiento y en los que la protección de la propiedad intelectual es muy importante (Maskus, 2000: 73-79).

En síntesis, los países de economías desarrolladas buscan hoy en día una mayor protección de los valores intelectuales, pues constituyen un importante eslabón en la obtención de grandes beneficios económicos y posterior elevación del nivel de vida de la sociedad; favorecen el comercio y sirven de catalizadores para el progreso técnico. Mediante el fomento de la invención y las nuevas tecnologías, aumenta la producción agrícola e industrial, se promueven las inversiones nacionales y extranjeras y se facilita la transferencia de tecnología.

\section{Los derechos intelectuales son necesarios en el orden social, cultural y humano}

En términos generales, desde una perspectiva social y humana se estima que los derechos de propiedad intelectual tienden a aumentar el valor y la calidad de vida de las personas, además de enriquecer el futuro de las naciones. Lo anterior se basa fundamentalmente en que una invención de cierto modo implica la solución de un problema técnico con cualidades funcionales o, por el contrario, se puede crear algo estéticamente agradable para satisfacer una necesidad o deseo humano, lo cual resultaría utilitario desde el punto de vista sensorial, social, cultural, mental, espiritual o religioso. Ésta es la base de la propiedad intelectual.

Desde el punto de vista cultural, los derechos intelectuales se encargan de permitir, fomentar y proteger dichas manifestaciones dentro de una comunidad. Según Anguita Villanueva (2005: 51-53), por una parte permiten el acceso a los bienes culturales en los que se exterioriza la cultura de los pueblos que ha de ser tutelado y garantizado por los poderes públicos; y por otro lado, garantiza el acceso y fomento a la creación. De lo contrario, traería consigo una dependencia intelectual respecto de otros, lo cual implica una dimensión económica elevada y a la vez una dependencia social a determinados productos que puede acabar con la concepción de democracia.

En relación al orden social, contribuyen a la lucha contra las enfermedades y la mejora de la salud de madres y niños, ya que con las investigaciones en materia de salud se crean nuevos medicamentos. Además, en el ámbito farmacéutico y biotecno-

4. La función exacta de los conocimientos y del cambio técnico ha sido tema de debate entre los economistas, pero éste es el punto de vista predominante. Para consultar un estudio no técnico sobre esta cuestión, véase Banco Mundial, (1999: 18-22). 
lógico, estos descubrimientos han tenido como resultado la creación de vínculos de cooperación entre empresas de todo el mundo y se promociona el acceso a la educación y la contribución al desarrollo sostenible. ${ }^{5}$

Según estudios recientes, la desigualdad no controlada podría poner en peligro la sostenibilidad de las economías, las sociedades y las comunidades. Éstas no solo deben entenderse y abordarse en términos de ingresos y riqueza: económicas, políticas, sociales, culturales y ambientales, sino aquéllas basadas en el conocimiento (Unesco, 2015).

Por ende, la población se ve beneficiada con estos aportes creativos, pues se van incorporando nuevas opciones de empleo, otras formas de comunicación, que son indispensables para el cuidado de la salud, lo cual trae consigo una mejor calidad de vida.

\section{Situación actual de la propiedad intelectual en los países en desarrollo}

Si se analizan los países en desarrollo y su gran diversidad, en lo relativo a sus circunstancias sociales y económicas y a su capacidad tecnológica, en el año 2002 éstos representaban aproximadamente el $21 \%$ del producto interno bruto mundial, ${ }^{6}$ aunque equivalen a menos del $10 \%$ mundial de los gastos en concepto de investigación y desarrollo.

En total, más del $60 \%$ de los pobres del mundo viven en países que poseen una capacidad científica y tecnológica significativa, y la gran mayoría vive en China y en la India. Éstos, junto con otros países en desarrollo más pequeños, poseen una capacidad de primera clase a nivel mundial en diversos ámbitos científicos y tecnológicos, entre los que figuran, por ejemplo, la tecnología espacial, la energía nuclear, la tecno-

5. Se calcula que en 1999 casi 1.200 millones de personas sobrevivían con menos de un dólar al día, y casi 2.800 millones vivían con menos de dos dólares al día. Alrededor del $65 \%$ de esta población residía en Asia del sur o del este, mientras que otro $25 \%$ estaba localizada en el África subsahariana. En 2001 murieron aproximadamente tres millones de personas a causa del sida, de los cuales 2,3 millones pertenecían al África subsahariana. La tuberculosis es responsable de casi 1,7 millones de muertes en todo el mundo. En el 2005 se produjeron 10,2 millones de nuevos casos. Más de un millón de personas mueren al año de malaria. En 1999, el número de niños que no asistía a la escuela primaria ascendía aún a 120 millones. El África subsahariana ostenta el menor índice de escolaridad de todo el mundo, con el $60 \%$. Puede consultarse el «Informe integrando los derechos de propiedad intelectual y la política de desarrollo», Comisión sobre Derechos de Propiedad Intelectual, 2002, disponible en http://www. iprcommission.org.

6. Datos del Banco Mundial, disponibles en http://bit.ly/2KDFRjd.

7. En 1994, China representaba el 4,9\% de los gastos en investigación desarrollo de todo el mundo, la India y Asia Central el 2,2 \%, América Latina el 1,9\%, el área del Pacífico y Asia del sureste el o,9 \% (se excluyen los países recientemente industrializados) y el África subsahariana el o,5 \% (Moore, Schneegans y Murugaiyan, 1998: 20-21). 
logía de la información, la biotecnología, los productos farmacéuticos y el desarrollo de software, entre otros. ${ }^{8}$

Sin embargo, la búsqueda de políticas de innovación que funcionen ha hecho posible que en América Latina, a partir del año 2015, las pequeñas y medianas empresas representen el $99 \%$ de todas las empresas en general y generen del $40 \%$ al $80 \%$ de empleos. Más del $40 \%$ del capital latinoamericano está basado en el conocimiento. ${ }^{9}$

En tanto, la estabilidad política, la ausencia de violencia y la efectividad y el control de la corrupción son vitales para alcanzar los objetivos de desarrollo a largo plazo y mejorar el desempeño científico y tecnológico de un país. Solo Chile, Costa Rica y Uruguay tiene resultados positivos hasta la fecha, los cuales han logrado que la inversión en conocimientos haya hecho posible la introducción de nuevas tecnologías, entre otras cuestiones (Unesco, 2015).

Los costos que supondría un sistema de propiedad intelectual «erróneo» en un país en desarrollo serían probablemente mayores que en los países desarrollados. La mayoría de los países desarrollados cuentan con sofisticados sistemas de regulación de la competencia para garantizar que los abusos de derechos de monopolio no perjudiquen los intereses de la sociedad. En Estados Unidos y en la Unión Europea, por ejemplo, estos sistemas son muy sólidos y cuentan con una larga tradición. Este no es el caso de la mayoría de los países en desarrollo, por lo que resultan especialmente vulnerables ante sistemas inapropiados de protección de propiedad intelectual.

Por otra parte, los científicos de los países en desarrollo pueden encontrar bloqueado el acceso a datos protegidos o quizás no cuenten con los recursos suficientes para obtener este acceso, o el sistema de propiedad intelectual puede obstaculizar o promover las investigaciones sobre enfermedades importantes o nuevos cultivos que, aunque afectan a los países en desarrollo, se llevan a cabo en los países desarrollados (Landes y Posner, 2003).

Las prácticas de los países desarrollados también pueden permitir la obtención de patentes sobre conocimientos o recursos genéticos provenientes de países en desarrollo, sin haberse llegado a un acuerdo previo para la distribución de los beneficios que se pudieran derivar de su comercialización. Es evidente, como resultado de esta protección, que se pueden imponer restricciones sobre las exportaciones de los países en desarrollo a los países desarrollados (Hovenkamp, Janis y Lemley, 2017).

8. Una pauta de la capacidad tecnológica es la cantidad de patentes estadounidenses que se obtienen anualmente. Entre los países en desarrollo a los que se concedió más de 50 patentes de Estados Unidos en 2001 figuran: China (266), India (179), Sudáfrica (137), Brasil (125), México (87), Argentina (58) y Malasia (56). A China (Taiwán) se le concedieron 6.545 y a Corea 3.763, pero estos países no están incluidos en la clasificación de países en desarrollo del Banco Mundial. Datos del Banco Mundial, disponibles en http://bit.ly/2KDFRjd.

9. «Economic survey of Latin America and the Caribbean 2015: Challenges in boosting the investment cycle to reinvigorate growth», ECLAC, agosto de 2015, disponible en http://bit.ly/2WOVF4b. 
Es por ello que los derechos de propiedad intelectual constituyen una herramienta al servicio del desarrollo económico y la creación de riqueza cuyo potencial no se ha explotado plenamente en todos los países, en particular, en el mundo en desarrollo, ${ }^{10}$ y la tendencia actual es lograr la protección de la propiedad intelectual en todo el mundo, por traer estos derechos sus aportes al producto interno bruto de los Estados, al crecimiento económico y al desarrollo social, personal y humano. Esta tendencia no es nueva, se ha venido produciendo durante más de cien años. Por otro lado, no solo se manifiesta dentro de las fronteras del país, sino que trasciende al mundo entero, convertido en un gran mercado de ideas, de creaciones y de productos culturales (Baylos Corroza, 2009: 65). ${ }^{11}$

\section{Estado de la cuestión en el derecho comparado}

Para el estudio de esta materia hemos escogido países de diferentes sistemas jurídicos, como el sistema norteamericano y el europeo, por contener importantes precedentes constitucionales. A la vez, revisaremos las constituciones latinoamericanas más relevantes, lo que nos permitirá evaluar aquellos elementos que fundamentan la necesidad de un respaldo constitucional a los derechos de propiedad intelectual.

A pesar de las diferencias que puedan existir entre los sistemas señalados, todas las constituciones han consagrado la protección constitucional expresa de los derechos intelectuales. Así, en primer lugar reconocen al autor o inventor como creador de una obra, la cual ha dotado de originalidad, de ingenio y creatividad intelectual (Antequera Parilli, 2009: 650 y ss.). Acto seguido, específicamente en lo que respecta a los usuarios, se encuentra la garantía de poder tener acceso al conocimiento que es producto de la creación del autor o inventor. Por último, se refieren al reconocimiento económico de las obras e invenciones concebidas como producciones particulares de los sujetos o de las empresas, exaltando su vinculación con la comunidad.

En las últimas cuatro décadas, la protección de los derechos intelectuales ha tomado fuerza en el debate internacional y son cada vez más los países que los protegen en sus constituciones, no solo como un incentivo que una sociedad otorga a la actividad creativa, sino también para garantizar una debida creación, protección, gestión y comercialización de los resultados científicos, tan importantes en el desarrollo económico, social, cultural y humano de los pueblos.

10. Así lo han sostenido tribunales (véase Atari Games Corp. con Nintendo of America, Inc., United States Court of Appeals for the Federal Circuit, 1990) razonando que las leyes de competencia económica y de patentes eran complementarias, pues ambas van dirigidas al fomento de la innovación, la industria y la competencia.

11. Acerca de este punto, la doctrina argentina sigue un análisis y esgrime que si los autores o inventores no contaran con un plazo mínimo de protección para disponer de forma exclusiva de la obra o invención fruto de su intelecto, la labor creativa perdería mucho de su incentivo (Mitelman, 2015: 2-6). 
No obstante, en el derecho comparado no se muestra uniformidad en el contenido que los textos constitucionales dedican a los derechos intelectuales. Sin embargo, esta diversidad podría sostenerse porque existe una base común de la cual parten todas las constituciones de nuestra órbita de cultura: la ordenación jurídica de la libertad (López Guerra, 1994:104). ${ }^{12}$

Los derechos intelectuales han sido reconocidos como derechos fundamentales tanto en la Declaración Universal de Derechos Humanos de 1948, como en el Pacto Internacional de Derechos Económicos, Sociales y Culturales de 1988, y en observancia a las disposiciones consagradas en estas declaraciones, las disposiciones constitucionales de distintos Estados así lo han estipulado.

\section{Protección de la propiedad intelectual en el derecho estadounidense}

En este punto debemos señalar que la Constitución de los Estados Unidos hace referencia, aunque no expresamente, a la propiedad intelectual. En ese sentido, en la Carta Magna de 1787 -la más antigua en vigor actualmente en el mundo- se otorga al Congreso la facultad para fomentar el progreso de la ciencia y las artes asegurando a los autores e inventores, por un tiempo limitado, el derecho exclusivo sobre sus respectivos escritos y descubrimientos (sección octava, numeral 8) (Vituri Perea, 2016: 411-431). En la Enmienda Diecisiete de 1992 se consagra la protección exclusiva a los autores e inventores sobre sus creaciones, los límites establecidos, la supremacía de los tratados internacionales que han sido ratificados por la nación, la observancia de estos derechos tanto desde el ámbito civil como penal, y nos remite a la legislación especial en la materia.

En lo que respecta al derecho de autor y las patentes, la Ley Federal estadounidense de propiedad intelectual está directamente avalada por la Constitución. En el caso de las marcas y otros signos distintivos, el gobierno federal solo tiene autoridad para legislar mediante su capacidad para regular el comercio (Mellor y otros, 2018: 2.003-

\footnotetext{
12. López Guerra distingue tres generaciones de derechos fundamentales, a saber: i) una primera generación, correspondiente al constitucionalismo liberal (siglos XVIII y XIX) en que el acento se pone en los textos constitucionales en derechos de clara dimensión individual: protección del individuo frente a amenazas externas por parte de los poderes del Estado, (derechos de libertad) y participación en la vida pública (derechos políticos); ii) una segunda generación de constitucionalismo social, a partir de la Primera Guerra Mundial, con constituciones en que a los derechos anteriores se añaden otros que tienen en cuenta las relaciones de los individuos con su entorno social - relaciones laborales, económicas, etcétera- y que suponen garantías de bienestar, o prestaciones materiales (educación, salud); iii) derechos de la tercera generación que protegen derechos colectivos, integrados por bienes antes considerados como sobreentendidos, y base de la misma vida, pero que comienzan a ser escasos, y cuya desaparición amenaza a la colectividad como un todo: derechos al medioambiente, a un entorno sano, al patrimonio cultural, etcétera.
} 
2.039). Cuando la Constitución otorga al Congreso la capacidad para legislar sobre el derecho de autor y las patentes, lo hace con una finalidad clara, que es promover el progreso de los sectores relevantes. Esta declaración se entiende como la base de la legislación estadounidense de propiedad intelectual, con la idea de fomentar el beneficio económico y aumentar el número de obras innovadoras y creativas disponibles para el público. ${ }^{13}$

Así, el gobierno federal se ha mantenido activo a la hora de legislar sobre la propiedad intelectual hasta donde le permite la Constitución. Por eso es importante apuntar que los derechos y obligaciones de una persona solo pueden ser entendidos a fondo tomando como referencia tanto la ley federal como la estatal.

\section{El estado de la cuestión en el derecho europeo}

Antes, creemos necesario precisar que la influencia francesa tanto en algunas legislaciones europeas como en las nacientes repúblicas americanas fue decisiva y se observa el predominio romanista de no distinguir entre el objeto del derecho y el derecho sobre el objeto.

En ese escenario, la categoría de derecho fundamental de la propiedad intelectual, y en particular el derecho de autor, queda explícita a través de las disposiciones contenidas en el artículo 27 de la Declaración Universal de los Derechos Humanos, en virtud del cual «toda persona tiene derecho a la protección de los derechos personales y materiales sobre su creación». ${ }^{14}$

En tal sentido, en la Constitución francesa del 3 de septiembre de 1791 (título 1, artículos 2 y 3), y en la posterior reforma del 4 de octubre de 1958, se reconoce el derecho de propiedad sobre las creaciones intelectuales, el derecho de los creadores a percibir beneficios derivados de su explotación, así como un derecho exclusivo sobre la creación intelectual temporalmente limitado.

\section{Los derechos intelectuales son reconocidos en España}

En España es muy raro encontrar referencias claras y concretas del derecho de propiedad intelectual antes de la Constitución vigente de 1978. O sea, la Constitución

13. «Reseña del marco jurídico y reglamentario de propiedad intelectual en los Estados Unidos de América», Organización Mundial de la Propiedad Industrial, disponible en http://bit.ly/2RjAs17. Véase Rosenthal Kwall (2010: 13-14) y Cornish, Llewelyn y Aplin (2013).

14. La Declaración Universal de Derechos Humanos, en su artículo 27, dice: «1) Toda persona tiene derecho a tomar parte libremente en la vida cultural de la comunidad, a gozar de las artes y a participar en el progreso científico y en los beneficios que de él resulten. 2) Toda persona tiene derecho a la protección de los intereses morales y materiales que le correspondan por razón de las producciones científicas, literarias o artísticas que sea autora». 
de Cádiz de 1812 llevaba a cabo un tratamiento del tema muy escaso. Se reconocía que todos los españoles pueden escribir, imprimir y publicar libremente sus ideas, por tanto, más que un enfoque realmente jurídico de la propiedad intelectual, es una intención política (libertad de expresión) (Álvarez Romero, 1979: 77-78).

Sin embargo, se va a reflejar después en las constituciones de 1837 y 1845. En estos textos se utilizan además expresiones parecidas, porque se habla de libertad de expresión o de libertad de creación artística o literaria: «A lo largo del siglo XIX es más frecuente la protección de los derechos intelectuales adoptada en la legislación especial, que lo que es el derecho de propiedad intelectual concretado en las constituciones» (Abarza y Katz, 2002: 9).

Ya en la Constitución de 1978 se encuentra un claro reconocimiento del derecho de propiedad intelectual que ha dado lugar a una interesante polémica. El artículo 20 está enmarcado en un capítulo dedicado a los derechos y a las libertades, dentro de la sección 1 relativa a los derechos fundamentales y a las libertades públicas. Aquí se ordenan los derechos relativos a la libertad de expresión. ${ }^{15}$

Este artículo que reconoce los derechos intelectuales ha producido en la doctrina dos posturas enfrentadas. La primera considera que los derechos intelectuales deben ser considerados como un derecho fundamental de la persona, es decir, un derecho inherente a la personalidad (Bondia Roman, 2007: 3-27) ${ }^{16}$ La otra postura doctrinal es la planteada por Diez Picazo (Vide, 2013), que considera que el artículo 20 se referirse a un derecho genérico e impersonal a producir o crear obras artísticas, por lo que no se protegería el resultado de la creación. De esta forma, los derechos fundamentales reconocidos en la Constitución, cuando se reconocen, necesitan una ley orgánica (De Román Pérez, 2005: 34-38). ${ }^{17}$

Es decir, en la doctrina española no se ha determinado aún si la actividad creativa que se protege por el derecho intelectual «se deriva de la constitucionalización del derecho de libertad de expresión reconocido en el artículo 20 de la Constitución española o se debe incardinar en la protección y reconocimiento de la propiedad como derecho funcionalizado que realiza el artículo 33» (Anguita Villanueva, 2005: 50-51), respecto al reconocimiento de la propiedad privada.

No obstante, en la Constitución vigente de España (1978) se hace un reconocimiento expreso de estos derechos. Por un lado, se declara formalmente su existencia; por otro, se regula el correspondiente mecanismo de garantía, el cual es necesario para la efectividad del derecho, pues la mera declaración no suele ser suficiente. A su vez, nos remite a la legislación específica.

15. La Constitución de España de 1978, artículo 20, apartado 1, punto b), reconoce y protege el derecho a la producción y a la creación literaria, artística, científica y técnica.

16. Similar opinión en el derecho español tiene Otero Lastres (2013) (véase Anguita Villanueva, 2014: 154). 17. Igual postura es defendida por Vide (2013). 
Así, la Ley de Propiedad intelectual 1/1996 no solo declara cuáles son los derechos intelectuales protegidos, sino que establece los mecanismos que garantizan el respeto a estos derechos. En el libro 3, título 1, recoge las acciones y procedimientos que no solo pueden plantearse en los supuestos de infracción de los derechos exclusivos de explotación, sino que también amparan y comprenden los derechos morales y patrimoniales que le corresponden a los creadores y la posibilidad de acudir a los tribunales con acciones civiles y penales como mecanismo de protección a los derechos de propiedad intelectual.

\section{Algunas consideraciones sobre la protección constitucional en Suecia}

En Suecia existe una monarquía constitucional. Por tanto, la Carta Magna de 1975 define cómo se gobierna el país. La Constitución establece la relación entre la toma de decisiones y el Poder Ejecutivo, así como los derechos y libertades fundamentales garantizados a los ciudadanos. Se compone de cuatro leyes que tienen precedencia sobre todas las demás: el Instrumento de Gobierno, la Ley de Sucesión, la Ley de Libertad de Prensa y la Ley Fundamental de Libertad de Expresión.

La Constitución contiene además disposiciones que reconocen los derechos de propiedad intelectual. En tanto, el Instrumento de Gobierno protege los derechos de autor de autores, artistas y fotógrafos en sus obras. En el capítulo 2, artículo 16 se plasma un reconocimiento expreso de las facultades morales y patrimoniales que le asisten a los creadores, los límites establecidos a estos derechos, así como los mecanismos de garantía para hacer efectiva esta protección. Se hace referencia al derecho de autor, no así a los derechos de propiedad industrial de manera expresa.

Por otra parte, la Ley Fundamental de la Libertad de Expresión tiene por objeto garantizar el libre intercambio de opinión, información completa y gratuita, y la libertad de creación artística, según lo dispuesto en el capítulo 1, artículo 1, párrafo 2. La Ley protege los medios de comunicación, como la televisión, el cine y la radio, a la vez que protege la libertad de creación artística. ${ }^{18}$

A su vez, en su artículo 19 expresamente se consagra que los autores, artistas y fotógrafos serán dueños de los derechos sobre sus trabajos, de conformidad con las previsiones que señale la Ley.

Por tanto, se evidencia un reconocimiento de los derechos de propiedad intelectual y se protege la libre creación artística, literaria y científica.

18. Vale aclarar que, si bien es cierto que no es lo mismo la libertad de expresión que el derecho de propiedad intelectual e industrial en su fundamento y materialización, sí son derechos que se complementan. 


\section{Recapitulación}

De este análisis podemos evidenciar cómo en los Estados Unidos, Francia, España y Suecia lo más importante es lograr el progreso de la ciencia y las artes. A partir de este reconocimiento en la Carta Magna, se garantiza en todas las constituciones la libertad de creación intelectual, artística y científica y se reconocen como derechos fundamentales.

Sin embargo, en las constituciones de Estados Unidos y Francia se protege expresamente el derecho moral y patrimonial de los autores e inventores por separado, y se otorga a éstos un derecho exclusivo sobre la creación temporalmente limitado, se reconocen los límites y se ofrecen garantías para la salvaguarda de estos derechos; no así en España, cuya protección constitucional solo reconoce estos derechos, pero no se determina el alcance; para lograr ello remite la protección a las normas específicas en la materia.

\section{Protección constitucional en los países latinoamericanos}

En los países latinoamericanos también hay un reconocimiento constitucional expreso de los derechos intelectuales, si se tiene en cuenta el rol económico que éstos han adquirido en los últimos tiempos, pues los bienes incorporales constituyen un renglón de máxima importancia, incluido hoy día en toda negociación o intercambio comercial entre países (Buainain, 2001: 4).

\section{Colombia}

Se aprecia que la Carta Magna de Colombia de 1991 consagra que el Estado protegerá la propiedad intelectual por el tiempo y mediante las formalidades que establezca la ley (capítulo 2, artículo 61), a su vez en los artículos del 70 al 74 del capítulo 2 se dispone expresamente que el Estado promueve y fomenta el acceso a la cultura, reconoce la igualdad y la dignidad de todos y promueve la investigación, la ciencia, el desarrollo y la difusión de los valores culturales de la nación.

Por otro lado, se manifiesta que la búsqueda del conocimiento y la expresión artística son libres, se crearán incentivos para que tanto las personas naturales como las instituciones desarrollen y fomenten la ciencia, la tecnología y demás manifestaciones culturales y se ofrecen estímulos especiales a quienes ejerzan estas actividades. A su vez, se protege el patrimonio cultural de la nación por parte del Estado, al igual que la actividad periodística para garantizar la libertad y la independencia profesional.

El concepto de "propiedad intelectual», acogido por el artículo 61 de la Constitución Política de Colombia, en concordancia con el artículo 2 numeral 8 del Convenio que establece la Organización Mundial de la Propiedad Intelectual es omnicomprensivo de diferentes categorías de propiedad sobre creaciones del intelecto, que incluye 
dos grandes ramas: la propiedad industrial y el derecho de autor, que aunque comparten su naturaleza especial o sui generis, se ocupan de materias distintas.

\section{Paraguay}

En Paraguay, la Constitución vigente de 1994 en su artículo 110 dispone que todo autor, inventor, productor o comerciante gozará de la propiedad exclusiva de su obra, invención, marca o nombre comercial con arreglo a la ley. Nótese que esta constitución no solo establece una disposición expresa para derecho de autor, sino que contempla además como derecho fundamental los derechos que posee el titular de un invento, marca o nombre comercial al amparo de las disposiciones legales contenidas en la ley respectiva. Como se puede observar, se protege tanto los derechos derivados de la propiedad industrial como del derecho de autor, aunque se reconoce solamente el derecho exclusivo que tienen los creadores sobre sus creaciones, sin detenerse a proteger ningún otro particular. Solo se remite a la ley específica en la materia.

\section{México}

La Constitución Política de los Estados Unidos Mexicanos de 2008, en su artículo 28, aclara que no constituyen monopolios «los privilegios que por determinado tiempo se concedan a los autores y artistas para la producción de sus obras y los que para el uso exclusivo de sus inventos se otorguen a los inventores y perfeccionadores de alguna mejora». Esta Constitución reconoce además como facultades del presidente: «Conceder privilegios exclusivos por tiempo limitado, con arreglo a la ley respectiva, a los descubridores, inventores o perfeccionadores de algún ramo de la industria».

Este derecho es contemplado en la Constitución mexicana porque se refiere a un derecho particular que va a reconocer el Estado y que va a proteger. El Estado no otorga ese derecho, el mismo nace de una idea y se plasma en materia, es intrínseco de su creador y es lo que le denominan derecho moral; por tanto, el autor y la obra son uno mismo. Esto quiere decir que el Estado no otorga ningún derecho, más bien lo reconoce, y con este reconocimiento lo resguarda para que su titular lo explote a su conveniencia, para generar una retribución económica a su favor (Colombet, 1997).

En este caso se reconoce expresamente el derecho exclusivo que tienen los creadores sobre sus obras o inventos, incluyendo el reconocimiento tanto de las facultades morales como patrimoniales y se remite a la legislación especial en la materia. No obstante, no se hace mención alguna a la observancia, ni los límites de estos derechos.

\section{Bolivia}

La nueva Constitución Política del Estado de Bolivia de 2009 retoma el rango constitucional de protección de la propiedad intelectual y extiende su alcance y ámbito de 
aplicación a los saberes y conocimientos tradicionales y colectivos. A la vez, expresa que «el Estado registrará y protegerá la propiedad intelectual, individual y colectiva de las obras y descubrimientos de los autores, artistas, compositores, inventores y científicos, en las condiciones que determine la ley» (artículo 102).

Asimismo, se dispone que el Estado garantizará el desarrollo de la ciencia y la investigación científica, técnica y tecnológica en beneficio del interés general. Se destinarán los recursos necesarios y se creará el sistema estatal de ciencia y tecnología.

Como se puede observar, en Bolivia las normas constitucionales protegen ambas ramas de la propiedad intelectual. Hacen referencia al derecho de autor, así como todo lo relativo a la propiedad industrial, se garantiza el desarrollo de la ciencia y la investigación, se remite a la legislación especial en la materia y se establece la creación de un Sistema Estatal de Ciencia y Tecnología como política para implementar las estrategias y así lograr el desarrollo de nuevas tecnologías.

\section{Argentina}

Por su parte, la Constitución de la República de Argentina de 1994, en su artículo 17 , dispone que «todo autor o inventor es propietario exclusivo de su obra, invento o descubrimiento por el tiempo que determine la ley».

A su vez, remite a la creación de leyes específicas en la materia de propiedad intelectual cuando en el capítulo cuarto, artículo 75, le da la atribución al Congreso de proveer lo relacionado al desarrollo humano, la defensa de la investigación, el desarrollo científico y tecnológico y su difusión y aprovechamiento, además de dictar leyes que protejan la identidad y pluralidad cultural, la libre creación y la circulación de las obras del autor, el patrimonio artístico y los espacios culturales y audiovisuales.

Por otro lado, se establece de forma expresa en el artículo 125, segundo párrafo, que las provincias y la ciudad de Buenos Aires deben promover el progreso económico, la ciencia, el conocimiento y la cultura.

\section{Venezuela}

En Venezuela, dispone la Constitución de 1999 que «la creación cultural es libre. Esta libertad comprende el derecho a la inversión, producción y divulgación de la obra creativa, científica, tecnológica y humanística, incluyendo la protección legal de los derechos de autor sobre sus obras. El Estado reconocerá y protegerá la propiedad intelectual sobre las obras científicas, literarias y artísticas, invenciones, innovaciones, denominaciones, patentes, marcas y lemas de acuerdo con las condiciones y excepciones que establezcan la ley y los tratados internacionales suscritos y ratificados por la República en esta materia» (artículo 98).

De igual forma, el artículo 99 expresa que «los valores de la cultura constituyen 
un bien irrenunciable del pueblo venezolano y un derecho fundamental que el Estado fomentará y garantizará, procurando las condiciones, instrumentos legales, medios y presupuestos necesarios. Se reconoce la autonomía de la administración cultural pública en los términos que establezca la ley».

Ya con la reforma constitucional del año 2007, la cual no se aprobó, se sostiene el carácter de derecho humano que tienen los creadores a propósito de la creación de sus obras, y también la consagración del derecho constitucional a la diversidad cultural. En el primer caso se trata de trasladar expresamente a la Constitución venezolana la disposición contenida en el artículo 27.2 de la Declaración Universal de los Derechos Humanos.

La consagración constitucional de la diversidad cultural, por su parte, debe atender al principio de respeto a los derechos humanos y las libertades fundamentales, y ser entendida como la multiplicidad de formas en que se expresan las culturas de los grupos y sociedades y ella se manifiesta no solo en las diversas formas en que se enuncia, enriquece y transmite el patrimonio cultural de la humanidad mediante la variedad de expresiones culturales, sino también a través de distintos modos de creación artística, producción, difusión, distribución y disfrute de las expresiones culturales, cualesquiera que sean los medios o tecnologías utilizados. ${ }^{19}$

Como lo afirma la propia Convención, las actividades de producción, difusión y distribución forman parte de la diversidad cultural, y con ese espíritu se ha de desarrollar constitucionalmente en Venezuela toda la normativa referida a esta materia, sin pretender inferir de ello una licencia de impunidad para el uso ilícito de obras, prestaciones y producciones protegidas por la propiedad intelectual.

\section{Perú}

En la Constitución Política del Perú de 1993 se hace mención a los derechos intelectuales estableciendo a la libertad de creación intelectual, artística, técnica y científica como un derecho fundamental protegido por la Constitución, por lo cual los autores no tienen limitación o restricción para desarrollar su libertad de creación. ${ }^{20}$

Asimismo, se establece que el autor ${ }^{21}$ tiene derecho a la propiedad sobre dichas creaciones y a su producto, por lo cual determina un derecho patrimonial que

19. Artículo 5 de la Convención Sobre la Protección y Promoción de la Diversidad de las Expresiones Culturales, aprobada por la Asamblea General de la Unesco de 2005.

20. La Constitución del Perú de 1993, en su artículo 2 señala que toda persona tiene derecho:

«8) A la libertad de creación intelectual, artística, técnica y científica, así como a la propiedad sobre dichas creaciones y a su producto. El Estado propicia el acceso a la cultura y fomenta su desarrollo y difusión».

21. Este artículo establece derechos para toda persona, por lo que no diferencia entre persona natural o jurídica. 
puede permitir al autor la explotación de su creación, y los demás derechos sobre esa propiedad. Los dos artículos que mencionaban la propiedad intelectual en la Constitución de 1979 han sido integrados en este único artículo de la Constitución de 1993. En su artículo 14 se reconoce como deber del Estado el promover el desarrollo científico y tecnológico del país. Es decir, primero se reconocen los derechos de propiedad intelectual como un derecho fundamental de la persona humana, cuando hace mención a la libertad de creación intelectual, artística y científica y posteriormente, se establece la garantía que brinda el Estado para la defensa de estos derechos.

Como apreciamos, en la Constitución se reconoce el derecho de la libertad de creación y el derecho patrimonial que le corresponde al autor o inventor, no hace referencia expresa al derecho moral que se le otorga al creador - originado en la doctrina francesa- que para Fernández Sessarego, es el llamado en la doctrina derecho personal del autor. ${ }^{22}$

El reto fundamental de los derechos intelectuales en el Perú es lograr una efectiva protección tanto de los autores o inventores sobre sus creaciones, como de la salvaguardia del acervo cultural.

\section{Ecuador}

Ecuador ha tenido una rica tradición legislativa en materia de derechos intelectuales y la nueva Constitución no ha estado ajena de esto, por lo que tuvo en cuenta este positivo desarrollo.

La nueva Constitución de 2008, a diferencia de otras normas constitucionales anteriores, reconoce en forma expresa la protección a la propiedad intelectual en varias de sus disposiciones (Corral Ponce, 2010: 159-160).

El artículo 322 contiene dos partes: en el primer apartado se reconoce la propiedad intelectual de acuerdo con las condiciones que señala la ley, y en la segunda parte de este artículo se prohíbe toda forma de apropiación de conocimientos colectivos en el ámbito de las ciencias, tecnologías y saberes ancestrales. Se prohíbe también la apropiación sobre los recursos genéticos que contienen la diversidad biológica y la agrobiodiversidad.

Este reconocimiento se entiende como una garantía que el Estado ofrece a los creadores e inventores, precisamente, con la remisión que hace la Constitución a la ley, en su artículo 1: «El Estado reconoce, regula y garantiza la propiedad intelectual

22. Gil Albarrán coincide con Fernández Sessarego en que: «La obra es el resultado del ejercicio de la libertad misma del ser humano. Constituye un derecho inalienable. Este derecho personal, al que equivocadamente se le suele conocer también como «moral», rindiendo culto a un lenguaje equívoco y a una tradición de origen francés» (Gil Albarrán, 2009: 16). 
adquirida de conformidad con la ley, las decisiones de la Comisión de la Comunidad Andina y los convenios internacionales vigentes en el Ecuador».

Por otra parte, el artículo 22 garantiza la protección del derecho de autor expresamente. Pero este artículo va más allá, ya que vincula y concibe de manera inseparable el desarrollo creativo, cultural y artístico con el derecho de propiedad intelectual como incentivo y recompensa necesaria para los creadores y artistas que generan cultura en ese país.

Aunque el lenguaje utilizado no es el más preciso, el objetivo y finalidad de este artículo es garantizar el derecho de autor sobre las creaciones en el ámbito literario y artístico. La mención que hace la Constitución a los distintos derechos que conforman el contenido del derecho de autor, como los morales, económicos o patrimoniales, así lo asevera.

Se reconoce la importancia del derecho de autor y su calificación como derecho humano, según lo ordena la Declaración Universal de los Derechos del Hombre. Se hace alusión al respeto a los tratados y convenios internacionales, sobre todo cuando se trata de aquéllos que regulan los derechos humanos.

Adicionalmente, el artículo 335 obliga al Estado a establecer «los mecanismos de sanción para evitar cualquier práctica de competencia desleal». ${ }^{23}$ Es un acierto que la Constitución sancione este tipo de ilícitos y castigue a quienes pretenden beneficiarse del esfuerzo y trabajo ajeno. Por ende, es realmente digno de relevar que exista una disposición de orden constitucional que castigue los actos contrarios a los usos o costumbres honestas en el comercio, toda vez que no es usual que a nivel constitucional se realice un reconocimiento expreso a la figura de la competencia desleal.

\section{República Dominicana}

En el caso de República Dominicana, el primer texto constitucional que contempló la propiedad intelectual como un derecho fundamental fue la Constitución de 1854 (artículo 8, numeral 17), diferenciándola de las cosas materiales (Adames Pérez, 2009). Desde entonces, más de 150 años han transcurrido y, en una u otra medida, todas las reformas constitucionales han mantenido la propiedad intelectual como un derecho fundamental.

La protección de la propiedad intelectual como un derecho constitucionalmente consagrado omite establecer derechos exclusivos sobre las creaciones e invenciones, si se entiende que la «libertad cultural» comprende el «derecho a la invención, pro-

\footnotetext{
23. Como es conocido, la mayor parte de las prácticas de competencia desleal se desarrollan en el marco de los derechos de propiedad intelectual: desacreditar a un competidor, aseveraciones falsas, diluir el activo intangible, inducir a error, uso comercial desleal de los datos de prueba u otra información confidencial o su divulgación, etcétera.
} 
ducción y divulgación de la obra creativa, científica, tecnológica y humanística». Así se aprecia en el texto del artículo 53 de la Constitución vigente de 2008, según el cual «toda persona tiene derecho a participar libremente en la vida cultural de la nación, al pleno disfrute de las artes, del progreso científico y cultural, así como a los beneficios que generen».

Por otro lado, establece además que la creación cultural es libre y comprende el derecho a la invención, producción y divulgación de la obra creativa, científica, tecnológica y humanística, incluyendo la protección legal de los derechos del autor sobre sus obras.

\section{Chile}

Los derechos de propiedad intelectual encuentran reconocimiento y protección en Chile. El texto constitucional asegura a todas las personas el derecho de propiedad sobre toda clase de bienes, corporales e incorporales. ${ }^{24}$ No obstante, no define lo que entiende por bien incorporal (Peñailillo Arévalo, 2007: 18). A pesar de ello, es válido destacar que su aplicación ha ido aumentando en virtud del citado artículo que, junto con proclamar la protección de la propiedad, consagra la propiedad sobre los derechos (toda clase de bienes corporales e incorporales). Así, la jurisprudencia de los tribunales chilenos ha reconocido el origen constitucional de los objetos de propiedad intelectual, dándole la protección que por tal carácter se merecen (Sandoval López, 2006: 66-68).

Al decir de Peñailillo Arévalo, en los casos en que se ha aplicado lo anterior, le permite concluir que los derechos son cosas y sobre estas cosas (incorporales) hay también una especie de propiedad..$^{25}$ Lo cual no significa que el dominio sobre las cosas incorporales sea una propiedad distinta a la que recae en objetos corporales (Alessandri Rodríguez, 1941). ${ }^{26}$ En este sentido, en el artículo 19, apartado 25, tercer párrafo de la Constitución chilena, se garantiza expresamente la propiedad intelectual, y serán de aplicación las mismas normas que regulan la propiedad común; solo se admite limitarlas a un plazo, según lo establecido en la ley especial. ${ }^{27}$

Resulta válido aclarar que, en materia de propiedad, la Constitución ha dispues-

24. Constitución Política de la República de Chile de 1980, en su artículo 19, apartado 24, establece: «El derecho de propiedad en sus diversas especies sobre toda clase de bienes corporales e incorporales».

25. El Código Civil de Chile, aprobado por Decreto 803, del 29 de agosto de 2000, del Ministerio de Justicia, establece en su artículo 583: «Sobre las cosas incorporales hay también una especie de propiedad». Véase para ampliar sobre el tema a Peñailillo Arévalo (2007: 54 y ss.).

26. Igual tesis es confirmada por Rozas Vial (1984: 85-87).

27. Tal como lo establece el artículo 19, apartado 25, tercer párrafo: «Se garantiza, también, la propiedad industrial sobre las patentes de invención, marcas comerciales, modelos, procesos tecnológicos u otras creaciones análogas, por el tiempo que establezca la ley». 
to una «reserva legal», en el sentido de que solo la ley puede establecer el modo de adquirir la propiedad, de usar, de gozar y disponer de ella y las limitaciones y obligaciones que deriven de su función social (artículo 19, numeral 24, inciso segundo). ${ }^{28}$

A pesar de ello, la Constitución ha introducido limitaciones - llámese también restricciones, obligaciones, cargas - a la propiedad privada, pero establece que nadie puede ser privado de su propiedad, ni de los atributos o facultades esenciales del dominio, solo en virtud de la ley expropiatoria, con derecho a indemnización (artículo 19, apartado 24, tercer párrafo).

Sin embargo, tal como hemos mencionado, el actual artículo 19, numeral 24, inciso primero de la Constitución vigente se refiere con el término «propiedad» a una genérica, puesto que reconoce que existen diversas especies; pero al mismo tiempo la califica de «derecho», con lo cual supone la existencia de un único derecho abstracto de propiedad, cuyas diversas especies tendrían que ser el derecho de dominio sobre las cosas corporales, la propiedad sobre las incorporales y la propiedad sobre las producciones del talento y del ingenio (Guzmán Brito, 2006: 142). Sin embargo, la Constitución de 1925 aseguraba «la inviolabilidad de todas las propiedades sin distinción alguna», a diferencia de la vigente de 1980. ${ }^{29}$

En este sentido coincidimos con Guzmán Brito, que refiere que lo señalado anteriormente contradice lo preceptuado en el Código Civil y en la legislación especial de propiedad industrial en Chile, para los cuales no existe un único derecho (real) abstracto de propiedad diversificada en especies, sino una propiedad distribuida en diversas especies identificables por su objeto: el dominio sobre las cosas corporales, los derechos reales sobre cosas corporales ajenas y los personales, y los derechos llamados intelectuales e industriales (Guzmán Brito, 2006: 143), lo cual es discutido en la doctrina civilista chilena.

En un primer punto, entonces, otra parte de la doctrina chilena coincide con Otero en que los derechos de propiedad industrial son algo más que simples derechos de propiedad. El autor dilucida el asunto en los siguientes términos: «Los derechos de propiedad industrial confieren a su titular una situación de dominio, cuya actuación se confía a su arbitrio y su objeto es un bien intangible, no una cosa. Por ende, no tienen por finalidad procurar a su titular el uso y disfrute de una cosa, sino la explotación de un bien inmaterial sobre el que recaen los derechos de propiedad industrial» (Otero Lastres, 2013: 50-51).30

Una segunda diferencia consiste en que se tratan de derechos temporales y son

28. Se entiende por función social de la propiedad que el dominio - en torno al cual giran todos los demás derechos reales- debe ser ejercido con consideración de los intereses de la sociedad y no solo de los particulares del propietario.

29. Ello proviene de la reforma de 1967, que establece un derecho de propiedad en sus diversas especies. 30. Igual criterio tiene Llobregat Hurtado (2007: 38-39). 
adquiridos por la creación personal de su titular. Así, una vez vencidos los plazos fijados por la legislación para cada bien intangible, se vuelven bienes comunes o de uso público y cualquiera puede explotarlos patrimonialmente (Mitelman, 2010:1516). Dicha aprensión la compartimos plenamente, aunque de igual forma, si revisamos el contenido patrimonial de la creación inmaterial, tiene sus afinidades con los derechos reales, por ser objeto de transmisión mediante los contratos de licencia y cesión y, por otorgar a su titular un derecho absoluto de exclusiva que tiene efectos erga omnes.

En tercer lugar, estos derechos nacen a través de un acto administrativo de concesió $^{31} \mathrm{y}$ tienen carácter territorial, por lo que su nacimiento dista bastante de coincidir con los modos de adquirir el dominio (Chijane Dapkevicius, 2011: 19).

Por último, la equiparación entre ambos derechos no es absoluta, si se tiene en cuenta que, en algunos supuestos, la exclusividad se extingue transcurrido cierto tiempo por el no uso, en contraste con la vocación de perpetuidad que parece consustancial a la propiedad ordinaria (Pérez de la Cruz Blanco, 2008: 15-16).

Entonces, se hace indispensable fijar en todo momento un cuidadoso equilibro de la función individual y social de la propiedad intelectual, equilibrio que implica conciliar los intereses de titulares y usuarios, con los del Estado en general (Schmitz Vaccaro, 2009: 343-344).

En otro sentido, el sistema de propiedad intelectual chileno busca proteger suficientemente estos derechos individuales, pero sin descuidar los intereses de la sociedad, teniendo en cuenta que estos derechos confieren a su titular la exclusividad de uso o explotación.

\section{A modo de resumen}

Hemos podido percatarnos de que en los países latinoamericanos se resalta el interés del Estado en promover y fomentar el acceso a la cultura, la investigación, la ciencia, el desarrollo y los valores culturales, y se remite en todo caso a la legislación específica en la materia. Sin embargo, los textos constitucionales de Venezuela y Ecuador son los más completos en materia de reconocimiento de los derechos intelectuales. En estas constituciones, el Estado otorga como derechos exclusivos de los creadores las facultades morales y patrimoniales y se tiene en cuenta la importancia de los tratados y convenciones internacionales suscritos y ratificados por los países en la materia de propiedad intelectual, así como el establecimiento de los límites y las garantías necesarias para la correcta protección, gestión y comercialización de estos derechos.

31. Algunos ya han planteado que los derechos de propiedad industrial nacen, por lo general, como consecuencia de una solicitud de registro en una oficina pública destinada al efecto, por lo que pueden ser calificados como «derechos registrales» (Llobregat Hurtado, 2007: 50; Otero Lastres, 2013: 50-51). 
A su vez, todos los países estudiados lo consagran como un derecho fundamental. En México y Perú se reconoce expresamente la distinción entre las facultades morales y patrimoniales que le corresponden a los creadores y la importancia de que se genere una retribución económica a favor de éstos.

Se destaca solo en el caso de Bolivia el establecimiento en la norma constitucional de la creación de un Sistema Estatal de Ciencia y Tecnología como política y la implementación de estrategias para el desarrollo de estos derechos. De igual forma, en Perú se establecen las garantías a los derechos intelectuales de manera expresa en un artículo de su cuerpo constitucional. Sin embargo, es válido resaltar que en Chile se protegen como meros derechos de propiedad común, con todos los inconvenientes que esto puede traer consigo, lo cual es discutible doctrinalmente.

En tal sentido, se evidencia que es indispensable crear una cultura de respeto a los derechos intelectuales, en la que los ciudadanos comprendan que respetar la legislación de propiedad intelectual es una obligación de toda la sociedad, y que el solo hecho de reconocer en la constitución la libertad de creación no es proteger y reconocer los derechos intelectuales. Como ha quedado demostrado con el estudio de las constituciones anteriores, se requiere una protección que abarque más.

Por tanto, en la mayoría de los textos constitucionales estudiados se evidencia que la propiedad intelectual es reconocida como un derecho fundamental, en el contexto y supeditado al acceso al conocimiento de toda la sociedad. En ese sentido, si la constitución excluye los derechos intelectuales como uno de los derechos fundamentales de los que goza todo autor o inventor, crea un desbalance injustificado. El fundamento de esta aseveración lo constituye el hecho clave de que la propiedad intelectual debe ser un estímulo para la creación y difusión de la cultura en un país, no un freno para el acceso a ella.

En tanto, el estudio de las normas constitucionales de algunos países nos conduce a concluir que el verdadero reconocimiento de los derechos intelectuales está en el logro de una protección efectiva de los autores e inventores sobre sus creaciones, así como dejar bien establecidos los límites a esos derechos y las garantías necesarias para la correcta protección, gestión y comercialización de los derechos de propiedad intelectual, el control de la transferencia de tecnología y la política de competencia, lo cual traerá consigo la salvaguarda del acervo cultural, el estímulo a los creadores y autores y el desarrollo social, económico y cultural de los pueblos. 


\section{Fundamento de la protección constitucional de la propiedad intelectual}

Los principios generales del derecho apoyados en la teoría de Kelsen ${ }^{32}$ determinan que la constitución es la norma suprema y predomina sobre cualquier otra del ordenamiento jurídico. En tanto, un reconocimiento de los derechos intelectuales en ella hace que prevalezcan y se les otorgue la importancia que reviste la protección a los derechos de los creadores en el mundo de hoy. Ello, con el propósito de incentivar el desarrollo económico, social, personal y cultural de los pueblos, lo cual sería un muro de contención infranqueable, para que la persona pueda ejercer los derechos que el orden constitucional le reconoce.

\section{Los derechos intelectuales son reconocidos como derechos humanos en el constitucionalismo moderno}

Se percibe a través de los años el cambio del paradigma filosófico, político y jurídico sobre la propiedad intelectual, al surgir la protección de los derechos individuales del ciudadano. Los derechos intelectuales como derechos personales vinculados con los de la personalidad se ubican en su protección constitucional como derecho fundamental de la persona humana o derecho humano. Tal cambio paradigmático se percibe en la Declaración de los Derechos del Hombre y del Ciudadano del 26 de agosto de 1789 .

Sin embargo, otra parte de la doctrina plantea que un derecho de propiedad intelectual es considerado un medio por el cual las naciones y sociedades pueden contribuir a promover la satisfacción de los derechos humanos, económicos y sociales. Aun cuando por algunos autores los derechos intelectuales son considerados derechos humanos, éstos no pueden estar subordinados a los requisitos que conlleva la protección de la propiedad intelectual. Los Estados conceden estos derechos durante periodos limitados - por lo menos en el caso de las patentes y los derechos de autor-, mientras que los derechos humanos son inalienables y universales (Rivera Santivañez, 2004: 230 y ss.). ${ }^{33}$

32. Hans Kelsen, jurista, filósofo y político austríaco (1881-1973), profesor de Filosofía del Derecho en la Universidad de Viena desde 1917 y profesor de muchas otras áreas jurídicas en varias universidades en el mundo. Kelsen defendió una visión positivista (o ius positivista) que llamó teoría pura del derecho: un análisis del derecho como un fenómeno autónomo de consideraciones ideológicas o morales, el cual excluyó cualquier idea de derecho natural. Sin embargo, el gran aporte de Kelsen es su pirámide normativa, un sistema de jerarquía de las normas que sustenta la doctrina positivista, según la cual toda norma recibe su valor de una norma superior, en la cual el vértice de la pirámide la es norma fundamental o carta magna: la constitución.

33. Existen autores que coinciden con este criterio, como Durán Ribera (2002: 177 y ss.). 
Lo importante aquí es intentar reconciliar, por una parte, los intereses de la sociedad en general a la hora de acceder a nuevos conocimientos y a los productos que se derivan de esos nuevos conocimientos y, por la otra, los intereses de esa misma sociedad en la promoción de la invención y de la creación para generar nuevos conocimientos y productos de los que puede depender el progreso material y cultural.

De este modo, si los derechos humanos pueden hacerse valer erga omnes y son reconocidos tanto frente al Estado como frente a las personas privadas y a todas las entidades de derecho privado y público como derechos fundamentales de la persona humana, se deben considerar entonces los derechos intelectuales como instrumentos de la política pública que otorgan privilegios económicos a particulares o instituciones públicas o privadas, únicamente con el propósito de contribuir al bien de la sociedad en general (Serrano, 2013: 9). Este privilegio es, por tanto, un medio para conseguir un fin y no un fin en sí mismo.

En tal sentido, el reconocimiento legal de la propiedad intelectual constituye una tutela de un derecho de una persona natural o persona jurídica - ya sea empresas o asociaciones económicas-que le corresponde a los autores o inventores sobre sus creaciones, con lo que su ejercicio se convierte en un mecanismo legal para impedir el uso de esta creación por terceros, no autorizados por el autor, inventor o titular. A la vez asegura la remuneración por los mismos sin limitar demasiado el acceso a ella, de modo tal que terceros puedan usarla y desarrollarla.

Por otro lado, permite conjugar la titularidad del derecho con la promoción y estímulo a la innovación tecnológica o difusión de la cultura, para que tales resultados propicien también un beneficio a la colectividad.

De este modo, el hecho de que el Estado promueva, fomente y garantice el acceso a la cultura, la innovación, la ciencia y la investigación, así como el reconocimiento de las facultades de los creadores, tanto las morales como las patrimoniales, incentiva a los mismos a continuar creando e investigando.

Otro elemento a considerar es el reconocimiento de la supremacía de lo dispuesto en los tratados internacionales suscritos y ratificados por los Estados y el establecimiento de los límites a estos derechos sin oponerse a las políticas públicas establecidas. Todo ello con el fin de que las políticas y normativas en materia de propiedad intelectual logren el justo equilibrio entre el estímulo a la creación e investigación científica y la garantía al acceso y la difusión del conocimiento científico y tecnológico.

Estos límites permiten precisamente que las sociedades se puedan beneficiar de los desarrollos y avances tecnológicos que ofrecen una mejor calidad de vida y, a la vez, se logre acceder a la información y la cultura como fuentes del enriquecimiento espiritual del ser humano.

Por otro lado, a nivel mundial se proporciona seguridad jurídica a través de la tutela constitucional de los derechos de propiedad intelectual sobre obras artísticas, científicas, tecnológicas, denominaciones de origen, variedades vegetales, marcas y 
otros signos distintivos. Se promociona el desarrollo de la sociedad del conocimiento mediante la difusión de la información sobre la propiedad intelectual, con el objeto de facilitar la transferencia tecnológica a los sectores productivos y de innovación.

Por tanto, la función principal de la propiedad intelectual es la de proveer incentivos para la creación intelectual, en una forma tal que se maximice la diferencia entre el valor del resultado protegido y el costo social de su creación, incluyendo el costo de administración del sistema.

Hay también limitaciones propias de cada régimen. ${ }^{34}$ Así, en un Estado en que otros derechos constitucionales están garantizados, el de propiedad intelectual tiene que hacerse compatible, antes que imponerse en su relación con otros valores constitucionales como el derecho a la cultura, a la información, a la educación, al desarrollo científico y tecnológico, a la libertad de expresión. Esto es algo que con frecuencia no se tiene en cuenta por quienes se dedican más a la apología que al estudio crítico de los derechos intelectuales (Vide, 2006: 372).

En ese orden, en un Estado de derecho la propiedad intelectual se ejerce como todo derecho en el marco constitucional. Los sistemas constitucionales modernos buscan activamente el balance y la mutua limitación cuando sea necesaria entre derechos constitucionales, antes que la exclusión o negación de unos por otros. Se aspira a lograr así el ejercicio simultáneo del mayor número de derechos posible.

En síntesis, el reconocimiento de la propiedad intelectual no puede convertirse en un freno para el acceso al conocimiento y la innovación; al contrario, debe ser un estímulo y difusión del mismo, sobre todo en los sectores de la salud, la agricultura y la alimentación. Es por ello la necesidad de que los organismos, instituciones, empresas y centros de investigación tengan establecido un sistema propio para garantizar la debida protección, gestión y defensa de los derechos de propiedad industrial.

\section{Tratamiento constitucional en Cuba}

La constitución ha sido identificada como el documento político más importante y trascendente para la vida de toda la sociedad, sobre todo porque su contenido incluye la regulación de las vías para realizar la conformación, organización, composición y funcionamiento de los órganos del Estado, la regulación de la situación jurídica de los individuos, las formas de propiedad y, en sentido general, el régimen económico.

34. Por ejemplo, aunque una obra literaria esté protegida por los derechos del autor, ésta puede ser citada e incluso reproducida, dentro de ciertos parámetros, para fines informativos, educativos o culturales. Aunque en principio no puede fabricarse legalmente un invento patentado salvo por el titular o los por él autorizados, existen licencias obligatorias mediante las cuales el Estado, en condiciones excepcionales, puede obligar al titular de la patente a transferir temporalmente y a cambio de un pago su derecho exclusivo. 
Es válido aclarar que en el escenario internacional se reconoce la atención priorizada que el Estado cubano le concede al desarrollo de la educación y la ciencia, lo cual se plasma constitucionalmente y tiene plena vigencia.

\section{Los derechos intelectuales no son reconocidos}

\section{en la vigente Constitución cubana de 1976}

La Carta Constitucional vigente en Cuba de 1976 no hace alusión directa a la propiedad intelectual, ni individualmente a los derechos de autor o propiedad industrial. Solo se encuentra amparada constitucionalmente la libertad de creación en todas las áreas y la promoción, estímulo y respaldo del Estado cubano a la actividad educacional, científico, técnico y cultural del país. ${ }^{35}$

De igual forma, no existe mención alguna a la protección de los derechos morales y patrimoniales que deben poseer los autores o inventores respecto de su creación. Sin embargo, se regulan dos preceptos constitucionales que dan la posibilidad de crear libremente obras artísticas, siempre y cuando no sean contrarias al sistema, lo cual va dirigido a promover la actividad creativa pero acorde a los principios y valores del Estado cubano. A la vez, se establece que la actividad creadora e investigativa en la ciencia es libre, pero el Estado estimula, viabiliza y prioriza la investigación que va dirigida a resolver los problemas que atañen el interés de la sociedad y al beneficio del pueblo.

Teniendo en cuenta lo anterior, consideramos que ello no es suficiente para alcanzar e impulsar las políticas en estas áreas, unido a que debe existir un reconocimiento expreso al incentivo y a la protección de los resultados investigativos, científicos y creativos en general.

Por estas razones debe establecerse que se reconozcan a las personas naturales y jurídicas los derechos morales y patrimoniales derivados de la creación intelectual conforme a la ley y a los tratados internacionales, los límites y las garantías esenciales a éstos. De igual forma, significar que los derechos adquiridos se ejerzan en correspondencia con las políticas públicas en materia tecnológica, industrial, comercial, de salud, agroalimentaria, cultural y social del país, como apuntamos anteriormente.

Como ya hemos expuesto, el fundamento de esta limitación lo constituye el hecho clave de que la propiedad intelectual no se convierta en un freno para el acceso al conocimiento y la innovación. Al contrario, debe ser un estímulo para la creación y difusión de dicho conocimiento.

35. En los artículos 9 y 39 en sus incisos e) y f) de la Constitución cubana se postula que el Estado estimula y viabiliza la investigación y prioriza la dirigida a resolver los problemas que atañen al interés de la sociedad y al beneficio del pueblo, así como que el Estado propicia que los trabajadores se incorporen a la labor científica y al desarrollo de la ciencia. 
En consecuencia, la supremacía que ostenta la Constitución se revierte con igual rango en sus contenidos normativos, por lo que los deberes y derechos consagrados en la constitución han de considerarse jerárquicamente superiores en la esfera jurídica, política e ideológica, de ahí que su desconocimiento o violación suponga un atentado contra la Constitución y el poder que ella jurídicamente expresa.

\section{Otros modos de protección en leyes especiales sobre la materia}

El objetivo básico de la protección de los derechos intelectuales en Cuba es incentivar la creación a través de una apropiada protección y reconocimiento a los autores e inventores, sin menoscabar el acceso a la cultura, la educación y el conocimiento, la difusión de nuestras obras y la defensa del patrimonio cultural y científico de la nación.

En ese sentido, aun cuando en la norma constitucional de 1976 no se evidencia un reconocimiento expreso a los creadores, término más general que incluye a autores de innovaciones tecnológicas y de las obras, como tampoco se protege la difusión y puesta en explotación económica de dichas creaciones, para vincularlas a los intereses de la sociedad, sí se han promulgado, al amparo de esta norma constitucional, nuevas disposiciones jurídicas específicas, atendiendo a la importancia de la protección de las obras e invenciones y ser Cuba miembro de importantes convenios internacionales sobre la materia, en especial el Convenio de París de la Organización Mundial de la Propiedad Intelectual y el Acuerdo de los Derechos de Propiedad Intelectual vinculados con el comercio (ADPIC) de la Organización Mundial del Comercio. ${ }^{36}$

Es necesario destacar que los cambios más relevantes de la legislación han sido en el ámbito de la propiedad industrial y sus diferentes modalidades, como las invencio-

36. Dentro de las normas específicas vigentes en Cuba, tenemos como las más importantes: la Ley 14 del 28 de diciembre de 1977, la Ley del Derecho de Autor; el Decreto Ley 290 de las Invenciones y Dibujos y Modelos Industriales del 1 de febrero de 2012; el Decreto Ley 291 de Protección de las Variedades Vegetales, aprobado el 20 de noviembre de 2011 y publicado en la Gaceta Oficial de la República de Cuba el 1 de febrero de 2012; el Decreto-Ley 292 de los Esquemas de Trazado de Circuitos Integrados, aprobado el 20 de noviembre de 2011 y publicado en la Gaceta Oficial de la República de Cuba el 1 de febrero de 2012; el Decreto Ley 203, de Marcas y Otros Signos Distintivos, del 24 de diciembre de 1999, que deroga lo relativo a marcas y otros signos distintivos en el Decreto Ley 68, regulando las relaciones jurídicas recíprocas que se establecen en la esfera de la solicitud, tramitación, gestión administrativa, concesión, administración y observancia de los derechos de propiedad industrial sobre las marcas y otros signos distintivos; la Resolución 63/200o, Reglamento del Decreto Ley 203, de la Ministra de Ciencia, Tecnología y Medio Ambiente, del 22 de mayo de 2000, que establece disposiciones complementarias de índole procesal al Decreto Ley 203; además, el Decreto-Ley 228 de las Indicaciones Geográficas del 20 de febrero de 2002 que regula la protección de las indicaciones geográficas como objeto de derechos de propiedad industrial; y la Resolución 21/2002 del 28 de febrero de 2002, que pone en vigor el Sistema Nacional de Propiedad Industrial. 
nes, modelos de utilidad, modelos y dibujos industriales, signos distintivos, incluidos las indicaciones geográficas y denominaciones de origen, las variedades vegetales y las topografías de circuitos integrados. No obstante, se ha quedado rezagada la rama del derecho de autor. La normativa en esta materia data del año 1977 y existe una legislación dispersa y fragmentada que complementa dicha ley.

\section{Actual reforma constitucional en Cuba}

Desde el año 2011, Cuba se encuentra en un proceso de importantes transformaciones en el orden económico y social, en especial la conceptualización del modelo económico y social cubano, que define los principios fundamentales que encauzan el perfeccionamiento legislativo. A partir de ello, se inició un proceso de reforma constitucional que culminó en marzo del 2019 con la proclamación, publicación y entrada en vigor de la nueva Constitución de la República.

La Constitución enaltece el papel de la ciencia en la economía al reconocerla en sus fundamentos económicos como un sector de especial interés y fomento por parte del Estado cubano. ${ }^{37}$

Lo anterior se vincula con los Fundamentos de la Política Educacional, Científica y Cultural recogidos en el título 3 de la nueva Constitución, los cuales de manera especial referencian la promoción por parte del Estado de la libertad de la creación artística en todas su formas de expresión, el reconocimiento de que la actividad creadora e investigativa en la ciencia es libre y el estímulo a la investigación científica con un enfoque de desarrollo e innovación, priorizando la dirigida a solucionar los problemas que atañen al interés de la sociedad y al beneficio del pueblo. ${ }^{38}$

Unido a ello, debemos destacar que una de las notas distintivas de la nueva Constitución es la ampliación del catálogo de derechos reconocidos a las personas naturales y jurídicas y el reforzamiento de las garantías de los mismos.

En este sentido, a diferencia de la Constitución del año 1976, la nueva Constitución sí regula expresamente a los derechos intelectuales en su artículo 62, al disponer que se reconocen a las personas los derechos derivados de la creación intelectual, conforme a la ley y a los tratados internacionales. Significa además que los derechos adquiridos se ejercerán por los creadores y titulares, conforme a la ley y en correspondencia con las políticas públicas.

Del análisis del articulado se evidencia:

37. El artículo 21 de la Constitución de la República de Cuba, de 11 de marzo de 2019, dispone que el Estado promueve el avance de la ciencia, la tecnología y la innovación como elementos imprescindibles para el desarrollo económico y social.

38. Véase el artículo 32 de la Constitución de la República de Cuba de 11 de marzo de 2019, en especial los incisos a) f) g) y el i). 
- Reconocimiento a las facultades morales y patrimoniales de las diferentes creaciones intelectuales, tanto en el ámbito del derecho de autor como de la propiedad industrial.

- Obligatoriedad de asumir los compromisos dispuestos en los tratados internacionales, por la importancia y prioridad que tienen en esta materia.

- El ejercicio de las facultades anteriores, en especial las patrimoniales, que se ejercerán según lo establecido en las normativas especiales, en las que deberá regularse no solo el alcance de las mismas, sino también las limitaciones al ejercicio de esos derechos, con el fin de que no se ejerzan de forma abusiva y puedan lesionar los intereses de los competidores, consumidores y el interés público o general.

- Prioridad de las políticas públicas, tanto para legislar en esta materia como para reconocer los derechos y sus limitaciones. En un país como Cuba, la salud, la educación, la agricultura, alimentación y el comercio, por solo destacar algunos, son sectores estratégicos para el desarrollo social, por lo que deberá existir una coherencia entre el ejercicio de los derechos intelectuales y el desarrollo de estos sectores fundamentales.

- En este contexto, se han venido aprobando en el país una serie de políticas públicas relacionadas con la esfera de la ciencia, la innovación y su protección, que requerirán de un respaldo normativo. Entre ellas se destacan la relativa a la reorganización del sistema de ciencia, tecnología e innovación, la de creación de parques científicos tecnológicos y vínculos de las universidades y las entidades de ciencia, tecnología e innovación con las entidades productivas y de servicios, la política de empresas de alta tecnología y la de propiedad industrial.

- La política de propiedad industrial tiene como principios básicos ordenadores, que se corresponden con el mandato constitucional, los siguientes:

- Salvaguardar el interés público para el desarrollo científico-tecnológico y socioeconómico.

- Permitir la adopción de las medidas necesarias para proteger la salud pública y la nutrición de la población.

- Contrarrestar el ejercicio abusivo de los derechos de propiedad industrial que se adquieran y las prácticas que limiten de manera injustificada el comercio o redunden en detrimento de la transferencia de tecnología.

- Asegurar la protección, gestión y comercialización de los derechos de propiedad industrial. 


\section{Conclusiones}

El objetivo principal de este trabajo es demostrar que es viable el reconocimiento constitucional de los derechos intelectuales en Cuba, si consideramos en cuenta el desarrollo económico, científico, social y cultural que está teniendo lugar. Así, de acuerdo con nuestro estudio, hemos llegado a la conclusión de que si bien desde el siglo XVIII aparece refrendada constitucionalmente la protección de los derechos intelectuales, en la actualidad por la importancia del conocimiento y la trascendencia en la economía de los países, se hace evidente la necesidad de proteger en la norma constitucional los derechos intelectuales, en virtud de que las sociedades y los Estados han advertido el valor de estimular el incremento y la difusión de los resultados de las creaciones intelectuales en los diversos campos del quehacer humano, para mejorar las condiciones de vida de los ciudadanos y ampliar los conocimientos científicos y técnicos.

En cuanto al derecho comparado, se debe apuntar que en el mundo no hay uniformidad en torno a la protección de los derechos intelectuales, no obstante, existe un reconocimiento constitucional expreso de estos derechos, a partir del rol económico que han adquirido en los últimos tiempos los bienes intangibles. Un estudio de la norma constitucional en diferentes países nos conduce a concluir que los Estados enfocan esta protección de forma mayoritaria en los siguientes aspectos: libertad de creación artística, literaria y científica; correcta protección de los derechos morales y patrimoniales de los creadores conforme a la ley y a los tratados internacionales; establecimiento de las garantías fundamentales a estos derechos; existencia de límites sin que se afecte la esencia de estos derechos; y creación de políticas públicas en materia tecnológica, industrial, comercial, de salud, agroalimentaria, cultural y social como estímulo para la creación y difusión de los conocimientos.

Finalmente, si tenemos en cuenta que este estudio se centra en la protección constitucional actual de los derechos intelectuales en Cuba, queda demostrado que la Constitución de 1976 resultaba insuficiente, al garantizar solamente la libertad de creación, en comparación con el modelo económico y social existente. No obstante, si se pretende el reconocimiento del hombre como creador y el estímulo a la investigación científica en función del desarrollo económico y social del país, se requiere perfeccionar el tratamiento constitucional de estos derechos y reconocer de forma especial las facultades de los creadores y titulares con los límites necesarios para que no se vulnere el acceso a la cultura, a la información y no constituyan un freno al cumplimiento de las políticas públicas en sectores estratégicos como la educación, la ciencia, la salud y la alimentación, por solo distinguir los más relevantes. Estos principios han sido contemplados en la nueva Constitución, de reciente entrada en vigor en Cuba, en correspondencia con el potencial científico del país y el impacto de la ciencia en la actividad económica. 


\section{Referencias}

Abarza, Jacqueline y Jorge Katz (2002). Los derechos de propiedad intelectual en el mundo de la OMC. Santiago: Cepal.

Adames PÉrez, Janet (2009). «La propiedad intelectual como derecho fundamental». Propiedad Intelectual, 2009: 6-10 Disponible en http://bit.ly/2KDJHIX.

Alessandri RodrígueZ, Arturo (1941). Curso de derecho civil. Santiago: Nascimiento.

Álvarez Romero, Carlos (1979). «La Constitución española y el derecho de propiedad intelectual». Boletín de ANABAD, 29 (1): 77-98. Disponible en http://bit. ly/2wZAfXw.

Anguita Villanueva, Luis Antonio (2005). «Derechos fundamentales y propiedad intelectual: Wl acceso a la cultura». En César Iglesias Rebollo (coordinador), Propiedad intelectual, derechos fundamentales y propiedad industrial (pp. 49-87). Madrid: Reus.

-. (2014). Constitución y propiedad intelectual. Madrid: Reus.

Antequera Parilli, Ricardo (2009). Estudios de derecho industrial y derecho de autor: Análisis de jurisprudencia comparada. Bogotá: Temis.

Banco Mundial (1999). World development report 1998/99: Knowledge for development. Washington DC.

Baylos Corroza, Hermenegildo (2009). Tratado de derecho industrial. Madrid: Civitas.

Bondia Roman, Fernando (2007). «Fundamentos, evolución y globalización de los derechos de autor». Revista de Derecho Privado, 6 (91): 3-27.

Buainain, Antônio Márcio (2001). «Estudio sobre la importancia económica de las industrias y actividades protegidas por el derecho de autor y los derechos conexos en los países de Mercosur y Chile». OMPI y Universidade Estadual de Campinas. Disponible en http://bit.ly/31UkGyB.

Chijane Dapkevicius, Diego (2011). Derecho de marcas: Contratación marcaria. Buenos Aires: B de F.

Corberá Martínez, José Miguel (2017). Los conflictos entre las marcas y las denominaciones sociales: Últimos desarrollos en el distema de marcas de la Unión Europea. Valencia: Tirant lo Blanch.

Colombet, Claude (1997). Grandes principios del derecho de autor y los derechos conexos en el mundo: Estudios de derecho. Madrid: CSIC.

Cornish, William, David Llewelyn y Tanya Frances Aplin (2013). Intellectual property: Patents, copyright, trademark and allied marks. Londres: Sweet \& Maxwell.

Corral Ponce, Alfredo (2010). «La propiedad intelectual y su tratamiento en la nueva constitución particular referencia a las negociaciones comerciales internacionales». Revista jurídica de Propiedad Intelectual, (2): 159 y 160. Disponible en http://bit.ly/2WQLNab. 
De Román PÉRez, Raquel (2005). «Naturaleza jurídica del derecho de autor». En César Iglesias Rebollo (coordinador), Propiedad intelectual, derechos fundamentales $y$ propiedad industrial (pp. 13-48). Madrid: Reus.

DuRán Ribera, Willman Ruperto (2002). «La protección de los derechos fundamentales en la doctrina y jurisprudencia constitucional». Ius et Praxis, 8 (2): 177-194.

Fernández-NóvoA, Carlos, José Manuel Otero Lastres y José Manuel Botana Agra (2013). Manual de la propiedad industrial. Madrid: Marcial Pons.

Gil Albarrán, Guillermo Edward (2009). Derechos de autor. Chimbote: Universidad Nacional de Santa.

GuZMÁn BRITO, Alejandro (2006). Las cosas incorporales en la doctrina y en el derecho positivo. Santiago: Jurídica de Chile.

Hernández Rodríguez, José Antonio (2011). «La importancia de los derechos de propiedad industrial. Monopolios legales para una competencia leal». Economía industrial, (379): 107-112. Disponible en http://bit.ly/2WRuc1I.

Hunter, Dan (2012). Intellectual property. Nueva York: Oxford University Press.

Hovenkamp Herbert, Mark D. Janis y Mark A. Lemley (2017). Ip and antitrust: An analysis of antitrust principles applied to intellectual property law. Nueva York: Wolters Kluwer.

LANDES, William M. y Richard A. Posner (2003). The economic structure of intellectual property law. Cambridge: The Belknap Press of Harvard University Press.

López Guerra, Luis (1994). Introducción al derecho constitucional. Valencia: Tirant lo Blanch.

Llobregat Hurtado, María Luisa (2007). Temas de propiedad industrial. Madrid: La Ley.

Machlup, Fritzy Edith Penroese (1950). «The patent controversy in the nineteenth century». Journal of Economic History, 10 (1): 1-29. DOI: 10.1017/So022050700055893.

Maskus, Keith (2000). Intellectual property rights in the global economy. Washington DC: Columbia University Press.

Mellor, James, David Llewelyn, Thomas Moody-Stuart, David Keeling, Iona Berkeley, Ashton Chantrielle y William Duncan (2018). Kerly's law of trademarks and trade names. Londres: Thomson Reuters.

Mitelman, Carlos Octavio (2015). Marcas y otros signos distintivos. Buenos Aires: Thomson Reuters.

Moore, Howard, Susan Schneegans y Pascale Murugaiyan (1998). World science report. Londres: Unesco.

Otero Lastres, José Manuel (2013). «Introducción». En Carlos Fernández-Nóvoa, Manual de la propiedad industrial. Madrid: Marcial Pons.

Peñailillo Arévalo, Daniel (2007). Los bienes, la propiedad y otros derechos reales. Santiago: Jurídica de Chile. 
Pérez de la Cruz Blanco, Antonio (2008). Derecho de la propiedad industrial, intelectual y de la competencia. Madrid: Marcial Pons.

Rivera Santivañez, José Antonio (2004). «Tribunal constitucional y protección de los derechos humanos». Estudios Constitucionales, 2 (1): 227-254. Disponible en http://bit.ly/2x3VlUQ.

Rosenthal Kwall, Roberta (2010). The soul of creativity: Forging a Moral Rights Law for de United States. Stanford: Stanford University Press.

Rozas Vial, Fernando (1984). Derecho civil: Los bienes. Santiago: Distribuidora Forense.

SANDOval López, Ricardo (2006). Marcas comerciales: Contiene la Ley 19.039, sobre propiedad industrial, reformada por la Ley 19.996, de 2005. Santiago: Jurídica de Chile.

Serrano, Yoleida (2013) «Derechos humanos y propiedad intelectual». Razón y Palabra, 16 (2-81): 1-24. Disponible en http://bit.ly/2x82l2J.

Schmitz Vaccaro, Christian (2009). «Propiedad intelectual, dominio público y equilibrio de intereses». Revista Chilena de Derecho, 36 (2):343-367. DOI: $10.4067 /$ So718-34372009000200006.

UNESCO (2015). Science report 2015. Luxemburgo.

VIDE, Carlos Rogel (2006). Los límites del derecho de autor. Madrid: Ediciones Madrid. -. (2013). En torno a la reforma de la ley de propiedad intelectual. Madrid: Reus.

Vituri Perea, Agustín (2016). El derecho de la propiedad intelectual en Estados Unidos. Madrid: Dykinson.

\section{Sobre las autoras}

Mabel Cándano Pérez es abogada. Licenciada en Derecho por la Universidad de La Habana, Cuba. Magíster en Gestión de la Propiedad intelectual, OCPI, Cuba y magíster en Derecho Constitucional y Administrativo, Universidad de La Habana. Magíster en Derecho Privado de la Universidad de Los Andes, Chile. Candidata a doctora por la Universidad de los Andes. Profesora de Derecho Comercial de la Universidad Autónoma de Chile. Su correo electrónico es: mabel.candano@uautonoma.cl. (iD) http://orcid.org/oooo-0002-1406-5134.

Marta Moreno Cruz es abogada. Licenciada en Derecho y doctora en Ciencias Jurídicas, ambas por la Universidad de La Habana, Cuba. Actualmente se desempeña como decana de la Facultad de Derecho de la Universidad de La Habana. Su correo electrónico es marta.moreno@lex.uh.cu. 


\title{
REVISTA CHILENA DE DERECHO Y TECNOLOGÍA
}

La Revista de Chilena de Derecho y Tecnología es una publicación académica semestral del Centro de Estudios en Derecho Informático de la Facultad de Derecho de la Universidad de Chile, que tiene por objeto difundir en la comunidad jurídica los elementos necesarios para analizar y comprender los alcances y efectos que el desarrollo tecnológico y cultural han producido en la sociedad, especialmente su impacto en la ciencia jurídica.

\author{
EDITOR GENERAL \\ Daniel Álvarez Valenzuela \\ (dalvarez@derecho.uchile.cl) \\ SITIO WEB \\ rchdt.uchile.cl \\ CORREO ELECTRÓNICO \\ rchdt@derecho.uchile.cl \\ LICENCIA DE ESTE ARTÍ́CULO \\ Creative Commons Atribución Compartir Igual 4.o Internacional
}

\begin{abstract}
La edición de textos, el diseño editorial
y la conversión a formatos electrónicos de este artículo

estuvieron a cargo de Tipográfica

(www.tipografica.cl).
\end{abstract}

